\title{
Application of Incentive Theory in Personnel Management in Colleges and Universities
}

\author{
Xiaojun Dai \\ Human Resources Office \\ Nanjing Forest Police College \\ Nanjing 210023, China \\ daixj@nfpc.edu.cn
}

\begin{abstract}
In the process of personnel management in colleges and universities, scientific use of incentive methods is an effective means to arouse teachers' enthusiasm and bring their creativity into full play. The importance of incentive theory in personnel management is self-evident. Psychologists in the 20th century studied how to motivate people from different perspectives and put forward various theories. On the basis of the analysis of related theories, this paper puts forward the principle of applying incentive theory in personnel management in colleges and universities based on literature, expert interviews, questionnaire and other methods, and propose four kinds of incentive methods combined with the reality.
\end{abstract}

Keywords-personnel management; colleges and universities; incentive theory; scientific allocation

\section{INTRODUCTION}

"Incentive" as a psychological term refers to the psychological process of starting and maintaining Incentive to reach the goal. The unmet need is the starting point of incentive. Through incentive, under the influence of some internal or external stimulus, one can always maintain a state of excitement. The "incentive" mentioned here refers to the incentive in personnel management. Applying the concept of "incentive" to personnel management is commonly called the issue of arousing people's enthusiasm.

Personnel management is to use scientific methods to organize, coordinate, train and allocate employees with certain material resources in a reasonable way, so as to keep the best proportion of human resources and material resources. At the same time, it can appropriately guide, control and supervise people's thoughts, psychology and behaviors so as to give full play to people's subjective initiative, to achieve the goal of the institution by making the best use of people, making the best use of their talents, and making them compete for success. In modern personnel management the influence of people's enthusiasm on institutional efficiency and efficiency is increasingly recognized by everyone, because no matter in universities, enterprises or other institutions, managers are almost all trying to give full play to people's intelligence and creativity in personnel management [1]. Only when people's enthusiasm, creativity and consciousness are fully mobilized, can they create efficient work performance, improve the institution's ability to survive, develop as well as innovate, and thus enhance its competitiveness. Therefore, modern personnel management pays great attention to how to arouse people's enthusiasm. James, a professor at Harvard University in the United States, has found in the study of incentives that employees who are paid on time can keep their jobs as long as they bring $20 \%-30 \%$ of their abilities into play. However, if fully stimulated, the ability can reach $80 \%-90 \%$, which is 3 4 times that of the former. This shows the importance of incentive.

Incentive is the process of creating conditions to meet various needs of employees, stimulating their incentive, and making them produce specific behaviors to achieve the institution's goals. Human behavior is dominated and driven by demand. Once the demand is realized, it is expressed in the form of behavioral incentive, which drives human behavior to act toward certain goals and pursue certain objects in order to satisfy himself or herself.

Therefore, colleges and universities should carefully analyze the characteristics of teachers, understand the needs of teachers, and achieve on-demand incentive in order to achieve the ideal effect. Based on the research results of Western organizational behavior theory and management practice, this paper discusses the problems that should be paid attention to in the process of college and university teacher' incentive.

\section{MAIN PRINCIPLES OF INCENTIVE}

\section{A. Focusing on the Combination of Material Incentives and Spiritual Incentives}

According to Maslow's and Audrey's Need Theory, different people have different needs, and the needs are various. There are not only material needs but also spiritual needs. Therefore, the way of incentive should also be the combination of material incentive and spiritual incentive, in which material incentive is the foundation and spiritual incentive is the basis. The two should be organically combined [2, 3]. Material incentives are aimed at people's material needs and provide corresponding material resources, such as wages and bonuses. Managers should pay enough attention to the material needs, because the material needs are the first and the basic needs of human beings.

At the same time, managers cannot ignore the role of spiritual incentive. Spiritual needs and material needs coexist, and spiritual needs can sometimes even substitute for material needs. Compared with material incentive, spiritual incentive can mobilize teachers' work enthusiasm at a higher level. Its 
incentive degree is large and its maintenance time is relatively long. College and university managers should make full use of it.

\section{B. Every teacher with the Opportunity to Participate in Collective Management}

At present, people regard participation in management activities as an important incentive factor in enterprise management in developed countries. Practice shows that participating in discussions on matters related to oneself can effectively enhance the member's concern for the collective and enhance the cohesion. Through the participation in management activities, on the one hand, teachers can enhance their understanding of their importance in the group, thus enhancing their self-esteem and self-confidence, especially when they feel that their collective success is inseparable from their own contribution and hard work, so that they will produce a sense of achievement [4]. On the other hand, participating in management activities will make teachers active in the group, thus satisfying their need for belonging and appreciation. At the same time, the respect gained will also enhance teachers' sense of security and sense of responsibility. That is way management by objectives emphasizes the active participation of all employees in process management, which can effectively mobilize the enthusiasm of employees.

\section{Creating Harmonious Interpersonal Relationships within the Group}

Behavioral science research believes that groups are stages of social activities where people meet the needs of safety, belonging, self-esteem and role recognition. A good, positive and harmonious interpersonal relationship can create a sense of security. Harmonious interpersonal relationships among groups enable people to obtain positive friendship and support, thus obtaining satisfaction of belonging. The status, identification, respect and care of individuals gained in the group, and the sharing of pain and happiness can meet the needs of people's self-esteem. Through satisfying the needs, people can often exchange views with everyone in order to gain support for some uncertain and uncertain views, thus enhancing the selfconfidence.

Moreover, through the exchange of views, people gain support and care, from which they have gained the recognition of their own values by the group, and thus have been satisfied with the realization of their own values. The group's good, positive and harmonious interpersonal relationship also forms strong control and adjustment to people's behavior norms, because the formation of group consciousness will enhance people's sense of responsibility and sense of accomplishment towards the group, as well as strengthen people's restriction on their own behaviors to comply with the group's interest requirements. At the same time, the behavior norms formed by the group make people consciously obey the group's norms under some pressure. The recognition, respect or trust gained by people in groups is also positive correction to people's behavior. Therefore, building a harmonious and good interpersonal relationship in the school is an important factor to arouse teachers' enthusiasm and consciousness, and is also a necessary condition for teachers to give play to their creativity.

\section{ApPLication of InCENTIVE MethodS}

\section{A. Paying Attention to the Level and Effectiveness of Incentive}

Teachers in colleges and universities are all well-educated intellectuals who contribute their intelligence and wisdom to the school's education in their own positions. However, due to differences in positions, personal abilities and efforts, there are also differences in the contributions made by each teacher to the college and university. Therefore, the incentive for teachers should also be properly divided into different levels, with emphasis and pertinence. Teachers with academic backbone and leaders in their chosen fields of learning who have made outstanding contributions or played a leading role should be given high-level incentives, while ordinary teachers should be given lower-level incentives. In this way, different levels of incentive stimulate different levels of teachers' enthusiasm, creativity and initiative.

Since the reform in China is lagging behind other countries, the high-level incentives, especially the special incentives in colleges and universities are generally less, insufficient in strength, but there are too many middle-level and low-level incentives poor in pertinence. This lack of level, focus and targeted incentive methods often enables high-level teachers to only get many middle-level and low-level incentives [5]. Although they can receive a lot of incentives, these incentives do not play an incentive role. If the middle-level teachers are given appropriate incentives, they are most likely to stand out as high-level talents. However, they have no choice but to get low-level incentives, while the low-level teachers receive little incentive. In the long run, the result can only make incentive insignificant for high-level and middle-level teachers. Certainly, it is not necessary to set extremely high incentives. Managers should pay attention to the effectiveness and pertinence of incentives and aim at motivating teachers' enthusiasm, initiative and creativity.

At the same time, in the process of incentive, managers should adhere to the principle of "Perfect-or-Nothings" and strictly control the level and quality of incentive according to standards.

\section{B. Objectively Evaluating Each Teacher's Performance}

Adams' theory of fairness holds that people are not only concerned about the absolute amount of incentive they get through their efforts, but also about the relationship between their own incentive and the incentive of others. After people get paid for their work, they will make some comparisons. If the incentive is not reasonable, they will be dissatisfied. Therefore, the university should objectively evaluate the performance of each teacher and adhere to the principle of fairness so as to reduce the negative consequences such as distraction and opposition caused by unfair distribution. The fairness theory focuses on "fairness in distribution", that is, the amount of incentive visible among individuals and fairness in distribution.

However, due to many factors, in fact, it is impossible to achieve the fairness of the final distribution. In comparison, in the current personnel management of colleges and universities, managers should consider "procedural fairness", that is, the 
procedural fairness used to determine the distribution of rewards [6,7]. Some studies show that distribution fairness has greater influence on employee' satisfaction than procedural fairness. On the contrary, procedural fairness is more likely to affect employee" institutional commitment, trust in superiors, and intention of mobility.

Therefore, colleges and universities should consider the openness and democratization of the decision-making process as much as possible when formulating distribution policies [8]. They should follow consistent and unbiased procedures and take similar measures to increase the sense of procedural fairness. By increasing the sense of procedural fairness, teachers will generally take a positive attitude towards leadership and institution even if they are not satisfied with the rewards, personal promotions, advancement and other related personal issues.

\section{Organically Combining University's Goals with Teachers' Personal Development}

The most lasting and strongest factor in encouraging people is the pursuit of personal development. Only when the incentive complies with teachers' personal development goals, can it encourage people to work voluntarily and consciously.

Therefore, colleges and universities should attach importance to the development of disciplines and the improvement of overall strength, as well as give teachers appropriate power and certain freedom to control their own teaching and scientific research activities and to take responsibility, so that teachers' work becomes more intrinsic and more challenging. It can enhance teachers' sense of accomplishment and self-realization. Only by respecting teachers' personal development in personnel management, especially guiding and encouraging teachers' personal development can colleges and universities effectively improve the overall level and strength of teachers and promote the development of colleges and universities.

\section{Making Full Use of Group Pressure and Group}

Psychology and Giving Full Play to the Exemplary

Leading Role of Key Member in Academy and Leaders in

Their Chosen Fields of Learning

Key member in academy and leaders in their chosen fields of learning are the backbone of the teacher group and also the main influencing factors of the psychological development of the leading groups in the teacher group. They set the examples with their image. The group behavior and psychological characteristics formed by their behavior and psychological characteristics are consistent with the goal of university's teachers' team construction, affecting other teachers in the group, attracting or promoting other teachers to keep in line with them as much as possible, that is, to keep in line with the goal of the group.
Therefore, as long as effective measures are taken to strengthen the construction of key member in academy and leaders in their chosen fields of learning, and the outstanding quality of key member in academy and leaders in their chosen fields of learning is ensured through a rolling management system that focuses on supporting and training, regular assessment and elimination of the fittest, the exemplary strength of key member in academy and leaders in their chosen fields of learning will also be ensured. By strengthening the power of role, it will form the positive guiding pressure on the ordinary teachers in the group, promote the formation of a positive and upward development trend in psychological behavior, and attract or urge the individual teachers to continuously improve their self-behavior through selfregulation according to the examples, thus achieving an indirect incentive effect.

\section{CONCLUSION}

Personnel management is a complicated and huge systematic project. Especially in today's Chinese society where the system is being reformed, it is even more complicated and of greater significance. In the process of personnel management, when the incentive theory is applied, various theories should be organically combined to achieve scientific and reasonable allocation so as to receive the expected results.

\section{REFERENCES}

[1] Li Binjiang, "Problems and Countermeasures of incentive mechanism for scientific research in universities," Science \& technology progress and policy, vol. 21, pp. 112-113, July 2016. (In Chinese)

[2] Xu Peng, Bai Guiyu, Chen Zhijun, "Research on the Relationship between Knowledge Workers' Participation Motivation and Innovation Performance: The Nonlinear Intermediary Role of Organizational Citizenship Behavior," Science of Science and Management of S.\&.T. (Monthly), vol. 37, pp. 77-80, May 2016. (In Chinese)

[3] Zhang Rong, Zhou Yi, "A peek at the incentive mechanis m of personnel management in the construction of faculty in Colleges and universities," Science and technology of west china, vol. 7, pp. 90-98, August 2008. (In Chinese)

[4] ZHANG She, "Research on the Personnel Management in College Based on Incentive-oriented Theroy,” Journal of yangling vocational \& technical college, vol. 7, pp. 73-75, April 2008. (In Chinese)

[5] Zhao Bingqi, "humane administration is what administration should be in all institutions of higher learning," Journal of PLA nanjing institute of politics, vol. 19, pp. 77-80, April 2003. (In Chinese)

[6] Qian Fu-liang, "Incentive Principles and Strategies of Personnel Administration in Universities and Colleges," Journal of changshu institute of technology, vol. 23, pp. 30-32, September 2009. (In Chinese)

[7] LI Shu-hua, "The Application of Incentive Mechanism in College HR Management,” Journal of lanzhou commercial college, vol. 21, pp. 125126, March 2005. (In Chinese)

[8] YOU YU-guan, “The Existing Problems in the University's Personnel Management System and Their Solutins,” Journal of fujian institute of education, vol. 9, pp. 23-26, July 2008. (In Chinese) 